FERREIRA, M.M.M.; FERREIRA, G.B.; FONTES, P.C.R. Produção do tomateiro em função de doses de nitrogênio e da adubação orgânica em duas épocas de cultivo. Horticultura Brasileira, Brasília, v. 21, n. 3, p. 468-473, julho-setembro, 2003.

\title{
Produção do tomateiro em função de doses de nitrogênio e da adubação orgânica em duas épocas de cultivo ${ }^{1}$
}

\author{
Magna Maria M. Ferreira² ${ }^{2}$ Gilvan B. Ferreira ${ }^{3}$; Paulo Cezar R. Fontes ${ }^{4}$; José P. Dantas ${ }^{5}$ \\ ${ }^{2}$ UEPB-EAAC, 58117-000, Lagoa Seca-PB; ${ }^{3}$ Embrapa Algodão, 58107-720 Campina Grande-PB; ${ }^{4}$ UFV-Dept ${ }^{\circ}$ Fitotecnia, $36571-000$ \\ Viçosa-MG; ${ }^{5}$ UEPB- CCT, 58109-753 Campina Grande-PB
}

\section{RESUMO}

A produção de frutos de tomateiro em resposta a doses de nitrogênio e à adubação orgânica foi avaliada em dois experimentos de campo conduzidos na primavera-verão e no outono-primavera, em 1999. Os experimentos foram instalados Universidade Federal de Viçosa, em solo da classe Argissolo Vermelho-Amarelo Câmbico. Em ambos, as doses de $\mathrm{N}$ aplicadas, na forma de nitrocálcio, foram $0,110,220,440$ e $880 \mathrm{~kg} / \mathrm{ha}$ e as doses de matéria orgânica, na forma de esterco bovino curtido, foram 0 e $8 \mathrm{t} / \mathrm{ha}$. Os experimentos seguiram o delineamento em blocos ao acaso, no arranjo fatorial $5 \times 2$, com quatro repetições. A produtividade foi influenciada pelas doses de $\mathrm{N}$, nos dois níveis de matéria orgânica, nas duas épocas. No experimento de primavera-verão, as máximas produções total, comercial e extra foram 44,78; 25,10 e 23,52 t/ha, obtidas com as doses de 530,2; 464,2 e $434,8 \mathrm{~kg} /$ ha de nitrogênio, respectivamente, sem adição de matéria orgânica; e 45,75; 25,87 e 24,53 t/ha, obtidas com as doses de 574,$2 ; 513,3$ e $599,8 \mathrm{~kg} /$ ha de nitrogênio, respectivamente, com adição de matéria orgânica. No experimento de outono-primavera, as produções foram 99,37; 78,87 e 69,93 t/ha, obtidas com as doses de 525,$4 ; 533,9$ e $557,5 \mathrm{~kg} / \mathrm{ha}$ de nitrogênio, respectivamente, sem adição de matéria orgânica; e 108,74; 87,08 e 78,09 t/ha, obtidas com as doses de 589,6; 575,3 e 557,4 kg/ha de nitrogênio, respectivamente, com adição de matéria orgânica. A adição de matéria orgânica ao solo aumentou a dose do adubo nitrogenado necessária à obtenção das máximas produções total, comercial e extra de frutos de tomate, em ambas as épocas de plantio.

Palavras-chave: Lycopersicon esculentum L., adubação nitrogenada, adubação orgânica, esterco bovino, produtividade, épocas de plantio.

\section{ABSTRACT}

Tomato plants production in relation to nitrogen doses and organic fertilization for two sowing times

The tomato plants yield as a result of nitrogen doses and organic fertilization was evaluated in two field experiments carried out in spring-summer and autumn-spring, in 1999. The experiments were carried aut at the Federal University of Viçosa, in a Cambic RedYellow Argisol. In both, the $\mathrm{N}$ doses applied, in the nitrocalcium form, were $0,110,220,440$ and $880 \mathrm{~kg} / \mathrm{ha}$ and the doses of organic matter, in the form of hardened bovine manure, were 0 and $8 \mathrm{t} / \mathrm{ha}$. The experimental design was of randomized blocks, in the factorial scheme $5 \times 2$, with four replications. The productivity was influenced by $\mathrm{N}$ doses, in the two levels of organic matter, at two periods. In the spring-summer experiment, the maximum total, commercial and extra productions were $44.78 ; 25.10$ and $23.52 \mathrm{t} / \mathrm{ha}$, obtained with the doses of $530.2 ; 464.2$ and $434.8 \mathrm{~kg} / \mathrm{ha}$ of nitrogen, respectively, without organic matter; and $45.75 ; 25.87$ and $24.53 \mathrm{t} / \mathrm{ha}$, obtained with the doses of $574.2 ; 513.3$ and $599.8 \mathrm{~kg} / \mathrm{ha}$ of nitrogen, respectively, with organic matter. In the autumn-spring experiment, the productions were $99.37 ; 78.87$ and $69.93 \mathrm{t} / \mathrm{ha}$, obtained with the doses of $525.4 ; 533.9$ and $557.5 \mathrm{~kg} / \mathrm{ha}$ of nitrogen, respectively, without organic matter; and 108.74; 87.08 and $78.09 \mathrm{t} / \mathrm{ha}$, obtained with the doses of $589.6 ; 575.3$ and $557.4 \mathrm{~kg} / \mathrm{ha}$ of nitrogen, respectively, with organic matter. The addition of organic matter in soil increased the nitrogen fertilizer dose necessary to obtain the tomato plant maximum production total, commercial and extra production, at both planting periods.

Keywords: Lycopersicon esculentum L., nitrogen fertilization, organic fertilization, bovine manure, yield, sowing times.

\section{(Recebido para publicação em 10 de janeiro de 2002 e aceito em 04 de julho de 2003)}

$\mathrm{O}$ crescimento e a produção do tomateiro e de outras culturas de importância econômica dependem, além de outros fatores, de adequado suprimento de nutrientes pelo solo às plantas. Sendo assim, para se obter alta produção de frutos comercializáveis é necessário conhecer os seus requerimentos nutricionais. Levando-se em conta os processos fisiológicos das plantas, o N, comparado aos outros nutrientes, tem maior efeito sobre as taxas de crescimento e absorção de elementos, sendo, portanto, mais importante em termos de controle da nutrição ótima das culturas (Huett \& Dettmann, 1988).
O crescimento e a produção em resposta ao $\mathrm{N}$ têm sido muito pesquisados em muitas espécies vegetais cultivadas e algumas silvestres. No tomateiro, a elevação no nível de $\mathrm{N}$ fornecido às plantas aumenta o peso de matéria seca das raízes, do caule, das folhas e dos frutos, a altura da planta, o número de folhas, a área foliar, o florescimento, a frutificação e a produtividade. Sob condições de campo, a nutrição ótima dessa cultura pode ser alcançada quando a quantidade aplicada de fertilizantes nitrogenados é igual a alta demanda que ocorre durante o período de crescimen- to dos frutos (Huett \& Dettmann, 1988, Singh \& Sharma, 1999).

As exigências nutricionais do tomateiro podem ser supridas pela adição ao solo de fertilizante químico, de matéria orgânica ou de ambos. A produção de frutos é possível com a prática alternativa de fertilização do solo com matéria orgânica (Rahman et al., 1997; Hunter \& Tuivavalagi, 1998) devido à alta concentração de N normalmente presente na mesma (Atiyeh et al., 2000). A disponibilidade de $\mathrm{N}$ para as plantas depende da taxa de mineralização da matéria orgânica, que vai depender da quantidade de $\mathrm{N}$ imobilizado

\footnotetext{
${ }^{1}$ Parte da Tese de Doutorado apresentada pelo primeiro autor a UFV, financiado pelo CNPq
} 
disponível na mesma; da temperatura, da umidade, do pH e da aeração do solo; das perdas do N por lixiviação e da relação carbono:nitrogênio do material. Foi constatado que valores mais altos de produtividade são obtidos quando se adiciona $\mathrm{N}$ mineral à matéria orgânica (Salek et al., 1981; Francis \& Cooper, 1998).

O tomateiro, devido à sua importância econômica, é explorado em ampla faixa de condições climáticas. No entanto, para que os rendimentos sejam ótimos, esta cultura tem requerimentos específicos. Na região Sudeste em altitudes em torno de $600 \mathrm{~m}$, as melhores produções são obtidas em épocas de precipitação e temperatura baixas, normalmente no período de outono-primavera. A chamada "época não ótima" caracteriza-se por elevadas temperaturas, altas umidade relativa, radiação solar e precipitação pluviométrica. Estas condições são consideradas adversas ao cultivo do tomateiro por favorecer o desenvolvimento de pragas e doenças, acelerar os processos de respiração, floração e formação dos frutos (Sam \& Iglesias, 1994), causar desenvolvimento vegetativo reduzido, aumentar a taxa de abortos florais e produzir frutos de baixa qualidade, diminuindo, desta forma, os rendimentos econômicos (Dominí et al., 1993). É possível que nesta época do ano a quantidade de $\mathrm{N}$ deva ser diferente da utilizada na época mais favorável.

Diante do exposto, o objetivo deste trabalho foi avaliar os efeitos de doses de nitrogênio e da adubação orgânica sobre a produção do tomateiro em duas épocas de plantio: primavera-verão e outono-primavera.

\section{MATERIAL E MÉTODOS}

Foram conduzidos dois experimentos, na primavera-verão e no outono-primavera. Os mesmos foram instalados em áreas localizadas na Horta do Fundão da Universidade Federal de Viçosa.

$\mathrm{O}$ experimento de primavera-verão foi conduzido no campo, a céu aberto, de 13 de novembro de 1998 a 11 de fevereiro de 1999. O de outono-primavera foi conduzido entre 14 de maio e 27 de outubro de 1999. Ambos foram conduzidos em solo da classe Argissolo VermelhoAmarelo Câmbico em duas áreas distintas, o qual apresentou as seguintes características químicas: $\mathrm{N}$ mineral $\left(\mathrm{N}-\mathrm{NO}_{3}\right.$
$\left.+\mathrm{N}^{-\mathrm{NH}_{4}}{ }^{+}\right)=39,81 \mathrm{~kg} / \mathrm{ha}$, na camada de $0-20 \mathrm{~cm} ; \mathrm{P}=21 \mathrm{mg} / \mathrm{dm}^{3} ; \mathrm{K}^{+}=51 \mathrm{mg} /$ $\mathrm{dm}^{3} ; \mathrm{Ca}^{2+}=0,9 \mathrm{cmol}_{\mathrm{c}} / \mathrm{dm}^{3} ; \mathrm{Mg}^{2+}=0,0$ $\mathrm{cmol} / \mathrm{dm}^{3} ; \mathrm{Al}^{3+}=0,3 \mathrm{cmol} / \mathrm{dm}^{3} ; \mathrm{H}+\mathrm{Al}$ $=3,3 \mathrm{cmol} / \mathrm{dm}^{3}$ e $\mathrm{pH}=4,3$; no experimento de primavera/verão; e $\mathrm{N}$ mineral $\left(\mathrm{N}_{-} \mathrm{NO}_{3}^{-}+\mathrm{N}^{-} \mathrm{NH}_{4}^{+}\right)=24,62,15,04 \mathrm{e}$ $13,12 \mathrm{~kg} / \mathrm{ha}$, nas camadas de $0-20,20$ 40 e 40-60 cm, respectivamente; $\mathrm{P}=86$ $\mathrm{mg} / \mathrm{dm}^{3} ; \mathrm{K}^{+}=85 \mathrm{mg} / \mathrm{dm}^{3} ; \mathrm{Ca}^{2+}=0,9$ $\mathrm{cmol}_{\mathrm{c}} / \mathrm{dm}^{3} ; \mathrm{Mg}^{2+}=0,0 \mathrm{cmol} / \mathrm{dm}^{3} ; \mathrm{Al}^{3+}=$ $0,3 \mathrm{cmol} / \mathrm{dm}^{3} ; \mathrm{H}+\mathrm{Al}=3,3 \mathrm{cmol}_{\mathrm{c}} / \mathrm{dm}^{3} \mathrm{e}$ $\mathrm{pH}=5,8$; no experimento de outono/primavera; e a seguinte granulometria (fração textural): argila $=50$ e $51 \%$, silte $=$ 16 e $12 \%$ e areia $=34$ e $37 \%$, nos experimentos de primavera/verão e outono/primavera, respectivamente.

Nos dois experimentos, os tratamentos foram constituídos de cinco doses de nitrogênio $(0,110,220,440$ e 880 $\mathrm{kg} / \mathrm{ha}$ ), em presença ou não de adubação orgânica. A fonte desse nutriente foi o nitrocálcio. Os dois níveis de matéria orgânica foram 0 e $8 \mathrm{t}$ /ha de esterco bovino curtido, em base seca. Os tratamentos foram distribuídos no delineamento em blocos ao acaso, com quatro repetições, perfazendo 40 parcelas.

As plantas de tomateiro cv. Santa Clara foram conduzidas no espaçamento de 1,0 m entre fileiras e $0,5 \mathrm{~m}$ entre plantas, no total de 28 plantas por parcela ( 4 fileiras com 7 plantas cada), sendo consideradas úteis as 10 plantas centrais da parcela.

As doses de $\mathrm{N}$ foram parceladas da seguinte maneira: $10 \%$ no momento do transplante, nos sulcos, e $15 \%$ aos 21 , $35,49,63,77$ e 91 dias após o transplante (DAT), em cobertura, ao lado das plantas, em meia-lua.

Nos dois experimentos, o tomateiro foi conduzido em haste única, com tutoramento em cerca cruzada, tendo sido podado três folhas acima da sexta inflorescência. As irrigações por sulco foram realizadas quando necessárias, em complementação ao volume de água precipitado pelas chuvas.

Os frutos foram colhidos quando a coloração estava avermelhada, no experimento de primavera-verão e cor-decana, no experimento de inverno/ primavera devido ao ataque de pardais.

Nos dois experimentos, os frutos sem defeitos foram classificados de acordo com o diâmetro transversal (D) em Graúdo AAA(D = 80,7), Graúdo AA
$(69,7=\mathrm{D}<80,7)$, Graúdo A $(60,0=\mathrm{D}$ $<69,7)$, Médio extra $(54,8=\mathrm{D}<60,0)$, Médio especial $(50,0=\mathrm{D}<54,8)$, Pequeno $(40,0=\mathrm{D}<50,0)$ e Refugo $(\mathrm{D}<$ $40,0)$. Foi considerada como produção de frutos extra, o somatório dos pesos dos frutos das quatro primeiras classes e como produção comercial o somatório dos pesos dos frutos das seis primeiras classes. A produção não-comercial de frutos correspondeu ao somatório dos pesos dos frutos com diâmetro $<40 \mathrm{~mm}$ (refugo) e dos frutos desqualificados devido a ocorrência de podridão apical, broca, rachaduras, Alternaria solani e outras anomalias. A produção total foi obtida pelo somatório das produções comercial e não-comercial.

Calculou-se também a produção ponderada ou equivalente dos frutos extra AA (PEAA), utilizando-se os fatores de ponderação de 1,$000 ; 0,625$ e 0,375 , baseando-se nos preços das classes extra AA (US\$ 4,37/cx), extra A (US\$ 2,73/cx) e extra (US\$ 1,64/cx) do tomate tipo Santa Cruz, comercializado em caixa tipo K, obtidos no mês de junho de 2000 junto a CEASA de Belo Horizonte (Ceasa, 2000).

Após a última colheita, em ambos os experimentos, as plantas úteis de cada parcela foram coletadas, cortando-se os caules rentes ao solo, e colocadas em sacos individuais. Cada saco foi pesado para a determinação do peso de matéria fresca. Posteriormente, tomou-se, da área útil de cada parcela, uma planta ao acaso, a qual foi seca em estufa de circulação forçada de ar a $70^{\circ} \mathrm{C}$, até peso constante, para determinação da percentagem de matéria seca. Esse valor foi utilizado no cálculo do peso de matéria seca de todas as plantas remanescentes da área útil e, em seguida, calculou-se o peso médio de matéria seca de cada área útil.

Os dados obtidos foram submetidos à análise de variância e de regressão, sendo que foram ajustados relacionando-se as variáveis dependentes às doses de $\mathrm{N}$ aplicadas, em cada nível de matéria orgânica. Os modelos de regressão testados foram: lineares, quadráticos e raiz-quadráticos. Escolheu-se o modelo com base no significado biológico, na significância dos coeficientes de regressão até $10 \%$ de probabilidade, pelo teste t, e no maior coeficiente de determinação.

A dose de $\mathrm{N}$ que proporcionou a máxima produção física equivalente a frutos extra AA (produção de máxima 
eficiência física $=$ MEF) foi obtida igualando-se a primeira derivada da equação correspondente à produção equivalente a frutos extra AA (PEAA) ao valor zero. A dose de $\mathrm{N}$ que proporcionou a máxima eficiência econômica (máximo retorno econômico $=$ MEE) foi obtida igualando-se a primeira derivada da equação correspondente a PEAA a 0,005 , correspondente a relação entre os preços do nitrogênio (US\$ 0,92/kg) e do tomate extraAA(US\$198,71/ t) obtidos no mês de junho de 2000 junto a CEASA de Belo Horizonte (Ceasa, 2000).

\section{RESULTADOS E DISCUSSÃO}

\section{Experimento de primavera-verão Produção de frutos}

A produção do tomateiro aumentou com a aplicação de $\mathrm{N}$, nos dois níveis de matéria orgânica. Sem adubação orgânica, as máximas produções total, comercial e extra foram 44,78; $25,10 \mathrm{e}$ $23,52 \mathrm{t} /$ ha, obtidas com as doses 530,2; 464,2 e 434,8 kg/ha de nitrogênio, respectivamente. Com adição de matéria orgânica ao solo, tais produções foram 45,$75 ; 25,87$ e 24,54 t/ha, obtidas com as doses 574,$2 ; 513,3$ e $599,8 \mathrm{~kg} / \mathrm{ha}$ de nitrogênio, respectivamente (Figura 1a). Tais produções máximas estão aquém daquelas encontradas em condições de campo por Silva et al. (1997), com a mesma cultivar utilizada no presente experimento (Santa Clara), e Guimarães (1998), com o tomate híbrido DéboraPlus, no mesmo local e época do presente experimento. Silva et al. (1997) encontraram o valor de $157,6 \mathrm{t} / \mathrm{ha}$ para a máxima produção comercial com a aplicação de 200 kg/ha de N. Já Guimarães (1998) encontrou os valores 62,9; 48,0 e 43,6 t/ha para as máximas produções total, comercial e extra, respectivamente, com a aplicação de $500 \mathrm{~kg} /$ ha de N.

Os baixos valores das produções máximas foram em virtude, talvez, das condições climáticas reinantes nessa época do ano (altas temperaturas, umidade relativa do ar e precipitações). Já foi demonstrado, em várias espécies, incluindo o tomateiro, que as altas temperaturas interferem negativamente no desenvolvimento reprodutivo da planta. Em geral, temperaturas altas resultam em maior percentagem de abortos florais (Willits \& Peet, 1998). Estudo desenvolvido por Moore \& Thomas (1952) indicou que temperaturas máxi-

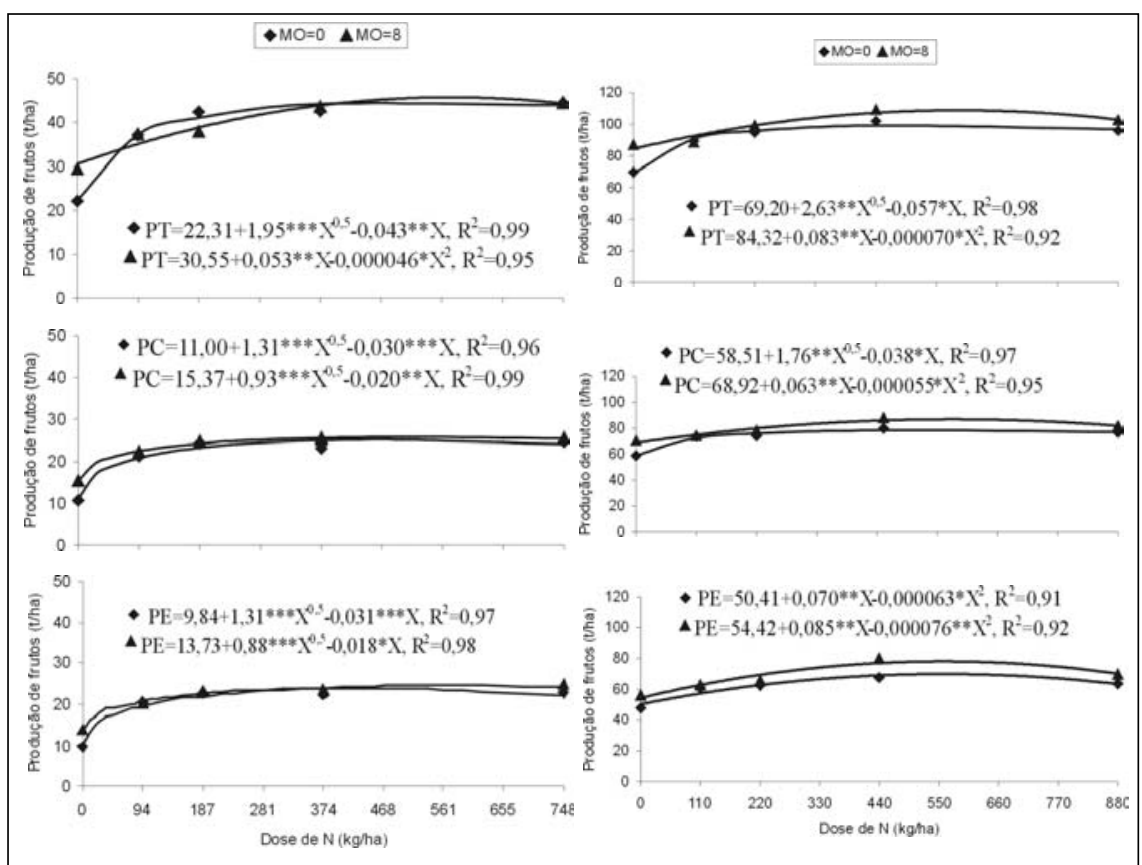

Figura 1. Produções total (PT), comercial (PC) e "extra" (PE) de frutos do tomateiro em função das doses de nitrogênio $(\mathrm{N})$ e da matéria orgânica ( $\mathrm{MO}$, em t/ha), dos experimentos de primavera-verão (a) e de outono-primavera (b). Viçosa-MG, 1999.

mas e mínimas acima de 32 e $21^{\circ} \mathrm{C}$, respectivamente, proporcionam baixa frutificação no tomateiro devido aos efeitos diretos sobre o pólen e outros tecidos reprodutivos, aos baixos níveis de carboidratos e aos desbalanços hormonais.

As doses de $\mathrm{N}$ responsáveis pela máxima produção total, nos dois níveis de matéria orgânica, foram superiores aos $200 \mathrm{~kg} / \mathrm{ha}$, que é a dose de $\mathrm{N}$ recomendada para o tomateiro estaqueado, no estado de Minas Gerais, em condições de campo, segundo a $4^{\mathrm{a}}$ e a $5^{\mathrm{a}}$ aproximações (Comissão de Fertilidade do Solo do Estado de Minas Gerais, 1989; Filgueira et al., 1999), e aos 280-380 kg/ ha de $\mathrm{N}$, doses recomendadas para o tomateiro estaqueado no estado de São Paulo, em condições de campo (Instituto Agronômico e Fundação IAC, 1996). Os elevados valores indicam baixa eficiência no uso do nitrogênio pelo tomateiro nesta época do ano, considerada pouco propícia ao desenvolvimento da cultura no campo. Possivelmente, as altas precipitações ocorridas durante o desenvolvimento do tomateiro contribuíram substancialmente para a lixiviação do $\mathrm{N}-\mathrm{NO}_{3}$ - aplicado e, conseqüentemente, para diminuição na eficiência do uso do fertilizante nitrogenado utilizado na adubação, conforme também constatado por Karaman et al. (1999), trabalhando com tomateiro nas condições da Turquia.

A produção equivalente a frutos extra AA ou ponderada possibilita melhor avaliação dos resultados, visto que fornece noção do seu possível valor econômico (Camargos, 1998). Tais produções de máxima eficiência física ficaram abaixo do valor encontrado por Guimarães (1998) para o híbrido de tomateiro Débora-Plus, o qual foi de 31,08 $\mathrm{t} / \mathrm{ha}$, o que se deveu a alta percentagem de frutos não comerciais constatada no experimento. Já as doses de N necessárias para a obtenção de tais produções ficaram acima da encontrada por Guimarães (1998), que foi de $500 \mathrm{~kg} / \mathrm{ha}$.

Quando não se adicionou matéria orgânica ao solo, a produção equivalente a frutos extra AA(PEAA) de máxima eficiência física foi de 15,20 t/ha, obtida com a dose 603,4 kg/ha de N (Figura 2a). A dose necessária para propiciar PEAA de máxima eficiência econômica foi $355,2 \mathrm{~kg} /$ ha de N, sendo esta produção igual a 14,70 t/ha. Com matéria orgânica adicionada ao solo, a PEAA de máxima eficiência física foi $15,98 \mathrm{t} / \mathrm{ha}$, obtida com a dose $564,8 \mathrm{~kg} / \mathrm{ha}$ de N. A dose necessária a PEAA de máxima eficiência econômica foi $310,2 \mathrm{~kg} / \mathrm{ha}$ de $\mathrm{N}$, sendo esta produção igual a 15,48 t/ha. Vê-se claramente que, nessa época do 


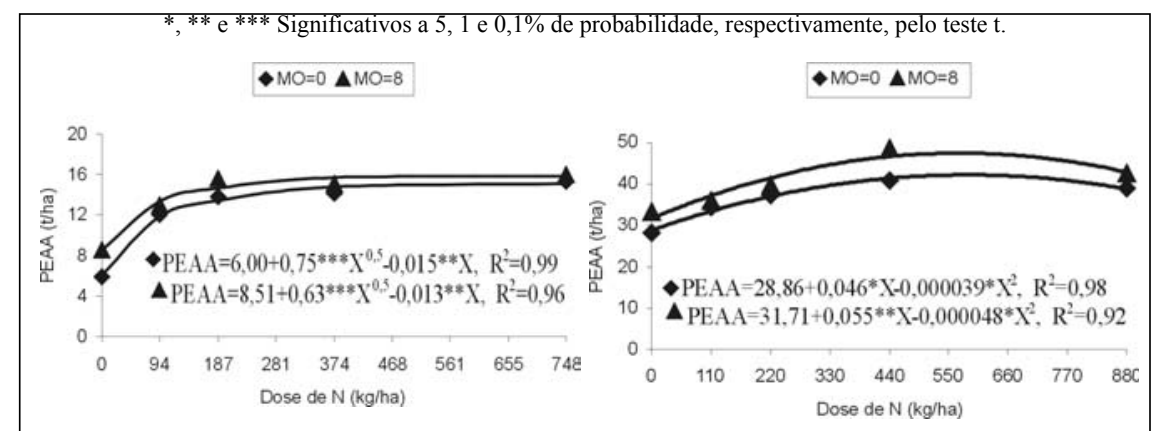

Figura 2. Produção equivalente a frutos extra AA (PEAA) ou ponderada do tomateiro em função das doses de nitrogênio $(\mathrm{N})$ e da matéria orgânica $(\mathrm{MO}$, em $\mathrm{t} / \mathrm{ha})$, dos experimentos de primavera-verão (a) e de outono-primavera (b). Viçosa-MG, 1999.

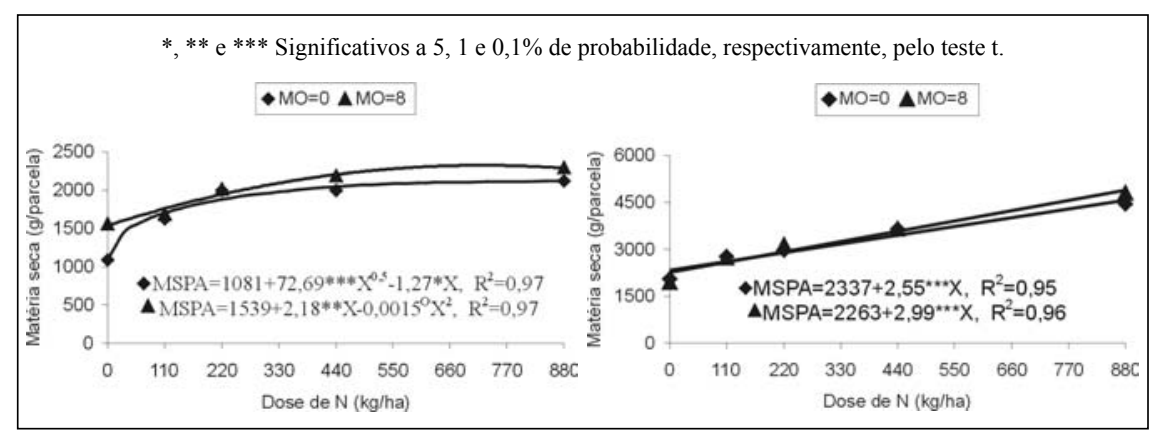

Figura 3. Matéria seca remanescente da parte aérea (MSPA) do tomateiro em função das doses de nitrogênio $(\mathrm{N})$ e da matéria orgânica (MO, em $\mathrm{t} / \mathrm{ha}$ ), dos experimentos de primavera-verão (a) e de outono-inverno (b). Viçosa-MG, 1999.

ano (primavera/verão), nos dois níveis de adubação orgânica, as doses de nitrogênio que causam produção máxima são bastante superiores àquelas do retorno econômico máximo, indicando não ser economicamente viável o uso de altas doses de fertilizantes nitrogenados.

Nesta época, nas doses 0 e 8 t/ha de matéria orgânica, respectivamente, seria possível atingir $90 \%$ da PEAA máxima (13,68 e 14,38 t/ha) aplicando-se 250,3 e $192,0 \mathrm{~kg} /$ ha de N, ou seja, 33,3 e 28,9\% da dose responsável pela PEAA máxima. Desta forma, para se obter produtividades entre 90 e $100 \%$ da PEAA máxima (de 13,68 a 15,20, sem adição de matéria orgânica, e de 14,38 a 15,98 t/ha, com adição) seriam necessárias doses de $\mathrm{N}$ variando entre 250,3 e 709,9 e entre 192,0 e 664,5 $\mathrm{kg} / \mathrm{ha}$. Isto é, houve a amplitude de apenas 1,52 e 1,60 t/ha na PEAA proporcionada pela amplitude de 459,6 e 472,5 kg/ha de $\mathrm{N}$, sem e com adição de matéria orgânica no solo, respectivamente.

\section{aérea}

A matéria seca da parte aérea, remanescente após a última colheita de fru- fotossintética aparente correlaciona-se positivamente com os teores de nitrogênio do solo (Tanaka et al., 1974c).

É importante ressaltar que nesta época, devido às condições climáticas, houve uma maior incidência de doenças. Assim, ao final do curto ciclo, as plantas estavam com péssima aparência, com intensos sintomas de doenças nas folhas e, muitas delas, caídas ao chão. Deste modo, não foi possível serem colhidas todas e avaliadas quanto à matéria seca remanescente da parte aérea após a última colheita dos frutos.

Experimento de Outono-primavera Produção de frutos

A produtividade do tomateiro aumentou com a aplicação de N, nos dois níveis de matéria orgânica testados, concordando com os resultados obtidos por Sainju et al. (2000). Na ausência da adubação orgânica, as máximas produções total, comercial e extra foram: 99,37 ; 78,87 e $69,93 \mathrm{t} / \mathrm{ha}$, obtidas com as doses de 525,$4 ; 533,9$ e $557,5 \mathrm{~kg} / \mathrm{ha}$ de $\mathrm{N}$, respectivamente. Com adição de matéria orgânica ao solo, tais produções foram 108,74; 87,08 e 78,09 t/ha, obtidas com as doses 589,$6 ; 575,3$ e $557,4 \mathrm{~kg} /$ ha de $\mathrm{N}$, respectivamente (Figura $1 \mathrm{~b}$ ).

As produções máximas estão acima do dobro das de primavera-verão. Isso ocorreu em virtude das condições climáticas na época de outono-primavera serem mais propícias à produção do tomateiro. Os rendimentos obtidos ficaram acima daqueles encontrados por Sampaio (1996) no mesmo local e época do presente experimento, os quais foram 53,9 e 38,8 t/ha para as produções total e comercial da cultivar Santa Clara, respectivamente, e por Valenzuela \& Erquiaga (1997) em cultivo comercial de tomateiro na Argentina, o qual foi de 70,5 t/ha. Fayad (1998), trabalhando no mesmo local e na mesma época do presente experimento, encontrou valores de 94,8 e 88,6 t/ha para as produções total e comercial, respectivamente, com a cultivar Santa Clara. Tais valores estão próximos dos constatados no presente experimento. Já Loures et al. (1998), trabalhando esta cultivar em condições de estufa, encontrou um valor de $162 \mathrm{t} /$ ha para a produção comercial, ou seja, bem acima dos observados na presente pesquisa. Segundo Ali et al. (1996), as condições climáticas, especialmente a temperatura, exercem papel fundamen- 
tal no crescimento e na produtividade do tomateiro. A temperatura influencia a viscosidade da água dentro da planta, a permeabilidade das membranas, a atividade metabólica, a absorção, a translocação e a assimilação de nutrientes e a força dos drenos no tomateiro. Todos esses fatores influenciam de maneira significativa as produções desta cultura.

As doses de $\mathrm{N}$ responsáveis pela máxima produção total, nos dois níveis de matéria orgânica, foram superiores à dose de $\mathrm{N}$ recomendada para o tomateiro estaqueado no estado de Minas Gerais pela $4^{\mathrm{a}}$ aproximação (Comissão de Fertilidade do Solo do Estado de Minas Gerais, 1989), e também pela $5^{\mathrm{a}}$ aproximação (Filgueira et al., 1999).

Seria possível obter $90 \%$ da PEAA máxima (38,03 e 42,77 t/ha) aplicandose 256,3 e $258,1 \mathrm{~kg} /$ ha de N, ou seja, 43,8 e $45,2 \%$ da dose responsável pela PEAA máxima, nas doses 0 e 8 t/ha de matéria orgânica, respectivamente. Desta forma, para se obter produtividades entre $90 \mathrm{e}$ $100 \%$ da PEAA máxima (de 38,03 a 42,26, sem adição de matéria orgânica, e de 42,77 a 47,52 t/ha, com adição) seriam necessárias doses de $\mathrm{N}$ variando entre 256,3 e 584,8 e entre 258,1 e 571,1 $\mathrm{kg} /$ ha de N. Isto é, as amplitudes de 4,23 $\mathrm{e} 4,75 \mathrm{t} /$ ha na PEAA corresponderiam às amplitudes de 328,5 e $313,0 \mathrm{~kg} / \mathrm{ha}$ de $\mathrm{N}$, sem e com adição de matéria orgânica ao solo, respectivamente.

As produções equivalentes a frutos extra AA (PEAA) ou ponderadas físicas máximas, constatadas nesta época, foram aparentemente superiores às do experimento de primavera/verão, porém as doses de $\mathrm{N}$ necessárias para atingirem tais produções foram semelhantes nos dois experimentos.

Quando não se adicionou matéria orgânica ao solo, a produção equivalente a frutos extra AA (PEAA) de máxima eficiência física foi $42,26 \mathrm{t} / \mathrm{ha}$, obtida com a dose $584,8 \mathrm{~kg} /$ ha de N (Figura 2b). A dose para a PEAA de máxima eficiência econômica, 42,12 t/ha, foi $525,8 \mathrm{~kg} /$ ha de N. Com matéria orgânica adicionada ao solo, a PEAA de máxima eficiência física foi 47,52 t/ha, com a dose $571,1 \mathrm{~kg} / \mathrm{ha}$ de N. A dose para a PEAA de máxima eficiência econômica, $47,41 \mathrm{t} / \mathrm{ha}$, foi $523,4 \mathrm{~kg} /$ ha de N. Isto é, sem e com matéria orgânica, as doses de nitrogênio para a máxima produção econômica foram 90 e $92 \%$ daquelas para a máxima produção física.

Matéria seca remanescente da parte aérea

A matéria seca da parte aérea, remanescente após a última colheita de frutos, aumentou linearmente com as doses de $\mathrm{N}$, sem e com adição de matéria orgânica ao solo (Figura 3b). O aumento contínuo na produção de matéria seca da parte aérea (Figura 3b) não foi acompanhado pelo aumento na produção total de frutos (Figura 1b), indicando que o fornecimento de doses muito elevadas de $\mathrm{N}$ não causou aumento na produtividade, apenas na biomassa verde.

Os valores encontrados na matéria seca remanescente da parte aérea no presente experimento (Figura $3 b$ ), em todos os tratamentos, foram, aparentemente, superiores àqueles do experimento de primavera-verão (Figura 3a). Segundo Sam \& Iglesias (1993), o desenvolvimento do tomateiro tem requerimento específico de temperatura e umidade. Também, as condições climáticas do período de outono-primavera desfavoreceram a incidência de doenças. Assim, após a última colheita dos frutos, ao contrário do que ocorreu no experimento de primavera-verão, as plantas apresentaram bom aspecto visual, com poucos sinais de doenças nas folhas e reduzida abcisão das mesmas.

A adição de matéria orgânica ao solo aumenta a dose do adubo nitrogenado necessária à obtenção das máximas produções total, comercial e extra de frutos de tomate, independente da época de plantio.

\section{AGRADECIMENTOS}

Os autores agradecem aos funcionários da Horta do Fundão da Universidade Federal de Viçosa que viabilizaram a execução dos experimentos de campo.

\section{LITERATURA CITADA}

ALI, I.A., KAFKAFI, U., YAMAGUCHI, I., SUGIMOTO, Y., INAGA, S. Effects of low root temperature on sap flow rate, soluble carbohydrates, nitrate contents and on cytokinin and gibberellin levels in root xylem exudate of sand-grown tomato. Journal of Plant Nutrition, v.19, n.3\&4, p.619-634, 1996.
ATIYEH, R.M., ARACON, N., EDWARDS, C.A., METZGER, J.D. Influence of earthwormprocessed pig manure on the growth and yield of greenhouse tomatoes. Bioresource Technology, v.75, n.3, p.175-180, 2000.

CAMARGOS, M.I. de. Produção e qualidade de tomate longa vida em estufa, em função do espaçamento e do número de cachos por planta. Viçosa: UFV, 1998. 81 p. (Tese mestrado).

CEASA. Boletim informativo diário de preços. Belo Horizonte: Secretaria de Agricultura, 2000. COMISSÃO DE FERTILIDADE DO SOLO DO ESTADO DE MINAS GERAIS. Recomendações para uso de corretivos e fertilizantes em Minas Gerais. 4a aproximação. Lavras, 1989. 76p.

DOMINÍ, M.E., PINO, M. de los A., BERTOLÍ, M. Nuevas variedades de tomate (Lycopersicon esculentum Mill.) para la epoca no optima. Cultivos Tropicales, v.14, n.2-3, p.94-97, 1993.

FAYAD, J.A. Absorção de nutrientes, crescimento e produção do tomateiro cultivado em condições de campo e estufa. Viçosa: UFV, 1998, 81p. (Tese mestrado).

FILGUEIRA, F.A.R., OBEID, P.C., MORAIS, H.J., SANTOS, W.V., FONTES, R.R. Tomate tutorado. In: RIBEIRO, A.C., GUIMARÃES, P.T.G., ALVAREZ V., V.H. (Eds). Recomendações para o uso de corretivos e fertilizantes em Minas Gerais. 5ª aproximação. 1999. p. 207-208.

FRANCIS, P.B., COOPER, P.E. Rate and timing of nitrogen fertilization on yield and gross revenue of fresh market tomatoes following a winter legume cover crop. Journal of Vegetable Crop Production, v.4, n.1, p. 55-65, 1998.

GUIMARÃES, T. G. Nitrogênio no solo e na planta, teor de clorofila e produção do tomateiro, no campo e na estufa, influenciados por doses de nitrogênio. Viçosa: UFV, 1998. 184p. Tese doutorado

HUETT, D.O., DETTMANN, E.B. Effect of nitrogen on growth, fruit quality and nutrient uptake of tomatoes grown in sand culture. Australian Journal of Experimental Agriculture, v.28, n.3, p.391-399, 1988.

HUNTER, D.J., TUIVAVALAGI, N.S. Effect of organic matter and frequent fertiliser applications on tomato production in a coralline soil. Journal of South Pacific Agriculture, v.5, n.2, p.63-65, 1998. INSTITUTO AGRONÔMICO \& FUNDAÇÃO IAC. Recomendações de adubação e calagem para o estado de São Paulo. 2. ed. Boletim Técnico $\mathrm{n}^{\circ} 100,1996.285 \mathrm{p}$.

KARAMAN, M.R., GULEC, H., ERSAHIN, S., JENSEN, A. Effect of different irrigation programs with nitrogen fertilizer application on nitrogen use efficiency and fruit quality in tomato. In: INTERNATIONAL SYMPOSIUM ON GENETICS AND MOLECULAR BIOLOGY OF PLANT NUTRITION, 6., 1999, Elsinore, Denmark. Proceedings..., Elsinore, Denmark, 1999, p.47-51.

LOURES, J.L., FONTES, P.C.R., SEDIYAMA, M.A.N., CASALI, V.W.D., CARDOSO, A.A. Produção e teores de nutrientes no tomateiro cultivado em substrato contendo esterco de suínos. Horticultura Brasileira, v.16, n.1, 50-55, 1998.

MOORE, E.L., THOMAS, W.O. Some effects of shading and parachlorophenoxy-acetic acid on fruitfulness of tomatoes. Proceedings of the American Society for Horticultural Science, v.60, n.12, p.289-294, 1952. 
RAHMAN, M.A., SAHA, J.H.U.K., CHOWDHURY, A.R., CHOWDHURY, M.M.U. Growth and yield of tomato as influenced by fertilizers and manure. Annals of Bangladesh Agriculture, v.6, n.1, p.71-74, 1997.

SAINJU, U.M., SINGH, B.P., RAHMAN, S., REDDY, V.R. Tillage, cover cropping, and nitrogen fertilization influence tomato yield and nitrogen uptake. HortScience, v.35, n.2, p.217221, 2000.

SALEK, R.C., ALMEIDA, D.L., OLIVEIRA, M.F., PENTEADO, A.F. Efeito do esterco de galinha e sua associação com fertilizantes sobre a produção do tomateiro no município de Teresópolis-RJ. Niterói: PESAGRO-Rio, 1981. 3p. (Comunicado Técnico, 70).

SAM, O., IGLESIAS, L. Caracterizacion del proceso de floracion-fructificacion en variedades de tomate en dos epocas de siembra. Cultivos Tropicales, v.15, n.2, p.34-43, 1994.
SAM, O., IGLESIAS, L. La floracionfructificacion de plantas de cinco variedades de tomate (Lycopersicon esculentum Mill.) sembradas en dos epocas. Cultivos Tropicales, v.14, n.2-3, p.64-70, 1993.

SAMPAIO, R.A. Produção, qualidade dos frutos e teores de nutrientes no solo e no peciolo do tomateiro, em função da fertirrigação potássica e da cobertura plástica do solo. Viçosa: UFV, 1996. $117 \mathrm{p}$. (Tese doutorado).

SILVA, E.C. da, ALVARENGA, M.A.R., CARVALHO, J.G. de. Produção e podridão apical do tomateiro (Lycopersicon esculentum Mill) podado e adensado sob influência da adubação nitrogenada e potássica. Ciência e Agrotecnologia, v.21, n.3, 324-333, 1997.

SINGH, A.K., SHARMA, J.P. Studies on the effect of variety and level of nitrogen on plant growth and development and yield of tomato hybrids (Lycopersicon esculentum Mill.). Annals of Agricultural Research, v.20, n.4, p.502-503, 1999.
TANAKA, A., FUJITA, K., KIKUCHI, K. Nutriophysiological studies on the tomato plant. I. Outline of growth and nutrient absorption. Soil Science and Plant Nutrition, v.20, n.1, p.57-68, 1974a.

TANAKA, A., FUJITA, K., KIKUCHI, K. Nutriophysiological studies on the tomato plant. III. Photosynthetic rate of individual leaves in relation to the dry matter production of plants. Soil Science and Plant Nutrition, v.20, n.2, p.173-183, 1974c. VALENZUELA, B.P., ERQUIAGA, J. Respuesta del tomate al sitio y a la fertilización. Revista de la Facultad de Ciencias Agrarias, v.29, n.1, p.1321, 1997.

WILLITS, D.H., PEET, M.M. The effect of night temperature on greenhouse grown tomato yields in warm climates. Agricultural and Forest Meteorology, v.92, n.3, 91-202, 1998. 